Technical Note

\title{
Ventilation management system for underground environments
}

\author{
Marc Bascompta Massanés ${ }^{\mathrm{a}, *}$, Lluís Sanmiquel Pera ${ }^{\mathrm{a}, \mathrm{b}}$, Josep Oliva Moncunill ${ }^{\mathrm{b}}$ \\ ${ }^{a}$ Iberpotash Chair in Sustainable Mining, Polytechnic University of Catalonia (UPC), Manresa, Catalonia, Spain \\ ${ }^{\mathrm{b}}$ Department of Mining and Natural Resources, Polytechnic University of Catalonia (UPC), Manresa, Catalonia, Spain
}

\section{A R T I C L E I N F O}

Article history:

Received 12 May 2014

Received in revised form 30 July 2015

Accepted 1 September 2015

Available online $\mathrm{xxxx}$

\section{Keywords:}

Underground ventilation

Geographic information system (GIS)

Health and safety

Efficiency

\begin{abstract}
A B S T R A C T
The management of the ventilation system is crucial to deal with efficiency, health and safety issues in an underground environment. This paper presents the design of a geographic information system - also known as GIS - capable to store, manipulate and extract results from the data collected regarding the ventilation features of an underground mine. The GIS can also be adapted to other types of underground infrastructures or include any additional parameter required.

A database of these parameters, in a case study, has been created taking into account two conditions: The changeable layout of the ventilation system during the evolution of the mine and the location of the control points, so the information can be analysed with the GIS in many different ways and purposes.

Therefore, the system can control the underground conditions in the long term and evaluate any change applied to the ventilation circuit.

The study has given insight of the most sensitive parts of a mine in terms of gases, temperature, air velocity and airflow - either from the principal or auxiliary ventilation circuit - finding a relationship among the airflow quantity, gases concentration and effective temperature.
\end{abstract}

(c) 2015 Elsevier Ltd. All rights reserved.

\section{Introduction}

Environmental conditions such as effective temperature, gases concentration or airflow have to be controlled and kept within an acceptable range in underground infrastructures where there is a presence of people. These types of space can be found in underground mining, civil infrastructures and tourist mines and caves, being of great concern the implementation of a management system for such purposes (Düzgün et al., 2011; Alfonso Abella et al., 2013).

In general, the most adverse conditions appear in the mining sector, where the control of the underground environment is compulsory. Therefore, it is important the implementation of a methodology for managing this question, otherwise occupational hazards and operating cost rise exponentially either by legal restrictions or by a reduction in the worker's performance. Thus, the system will have to take into account all the ventilation parameters to deal with efficiency and health and safety issues at the same time. However, their connection is usually overlooked. According to Reddy (2009), up to $60 \%$ of the mining operating costs are attributable to mine ventilation, while the relationship among

\footnotetext{
* Corresponding author.

E-mail addresses: mbascomptem@gmail.com (M. Bascompta Massanés),sanmi@ emrn.upc.edu (L. Sanmiquel Pera), josep@emrn.upc.edu (J. Oliva Moncunill).
}

hygienic conditions, accidents and worker's efficiency has been previously mentioned by Garcia-Herrero et al. (2012).

Many investigations have been focused on occupational health and safety or efficiency (Allen et al., 2008; Kurnia et al., 2014), and some of them use a software to optimise or modelling parts of the ventilation system (Hargreaves and Lowndes, 2007; Toraño et al., 2011; Cheng and Yang, 2012; Likar and Čadež, 2000). Moreover, the usage of GIS in mining is quite frequent, varying from management (Düzgün et al., 2011) to pollutants emission (Puliafito et al., 2002) or subsidence (Kim et al., 2006) among other applications. However, it is rarely used for the management of ventilation matters (Liu et al., 2004; Salap et al., 2009) and not even mentioning the efficiency concept. Despite that, a geographic information system is able to provide the tools, frameworks and understanding of the real situation inside a mine (Saleh and Cummings, 2011) so programs and procedures can be implemented to ensure health and safety objectives (Akcil, 2006) through a database of the underground environment features such as airflow, gases or air pressure drop.

The aim of this paper is to propose a system for managing an underground environment that is able to analyse the real conditions in the long term and provide insight for controlling the current situation and future improvements in terms of working conditions and efficiency of the mine. Its creation will also give a new utility for a GIS. 


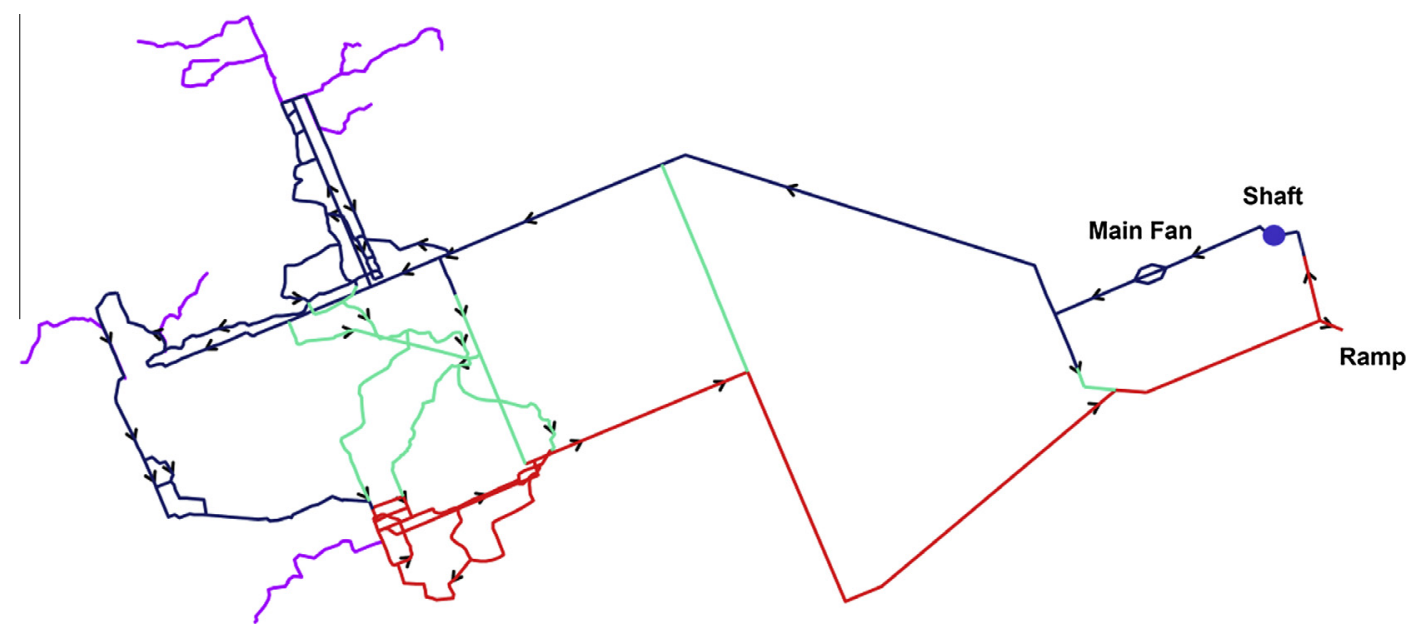

Fig. 1. Scheme of the ventilation circuit.

The software fits perfectly with what is demanded in a place that spreads out every day and generates a huge quantity of interconnected spatially referenced information from monitoring a dynamic environment (Gibert et al., 2006). Having the possibility to analyse the data and finally extract conclusions in the form of tables, graphs and even convert the information to other software formats.

\section{Case of study: Mine description}

The investigation has been focused on a Spanish mine, which is exploiting potassium from the Catalan basin. The resource is exploited by means of a room and pillar system $500 \mathrm{~m}$ below the surface and the connection underground-surface is done through a shaft (intake) and a ramp (return). The main fan is placed at the beginning of the ventilation circuit, leading the airflow by temporary stoppings, curtains and doors. Meanwhile the auxiliary circuit provides clean air to every working face through a duct system. Fig. 1 is a scheme of the mine described above with the most important elements labelled. The image is one of the configurations created using the GIS and it displays the parts of the ventilation system in different colours: The intake is in colour sea blue, the return red, ${ }^{1}$ the leakage sky blue and the auxiliary system pink. The airflow direction has also been indicated.

Initially, the staff of the mine had not stablished the position of the ventilation control points and an adequate analysis of the data collected was almost impossible when the factor time was included in the assessment, being needed a systematic method.

Salap et al. (2009) exposes an interesting approach for managing this type of environments, but it does not take into account all the parameters required for fully control the environmental conditions in this case, so it has been created a GIS based on the factors mentioned by Cheng and Yang (2012) and McPherson (2009) regarding efficiency and safety variables.

\section{Methodology and database}

Among all the software available, it has been chosen the ArcGIS because of its user-friendly platform, it is widespread in many different sectors and can be employed in any underground space apart from mines. The version used is the 9.3, but anyone would suit.

\footnotetext{
${ }^{1}$ For interpretation of colour in Fig. 1, the reader is referred to the web version of this article.
}

\subsection{Data collection}

First, several points standing for the real conditions of the whole ventilation system have been determined based on the following rules:

- Principal circuit: Important places from the intake, return and leakage airways.

- Auxiliary circuit: Variable position corresponding to the continuous miner location in the working faces.

Parameters used in the paper were obtained in situ and measured by conventional methods. They were taken during the same period of time in two consecutive days every month, one for the principal circuit and other for the auxiliary. Overall, 753 points have been stored in an Excel file since April 2009, 594 from the principal and 159 from the auxiliary.

The validity of the analysis depends on the method used for obtaining the data. The lower the reliability of the outcome is, the more difficult it is to detect the effects of an intervention (Lipsey, 1990), typically because of instability in what is measured and variations in the instrument (Shannon et al., 1999). For this reason, the equipment is calibrated regularly and measures are taken twice.

\subsection{Data format and characteristics}

The initial information consisted of several maps in dxf format (AutoCad) containing the layout of the mine along the time and the database in xls (Excel) with the ventilation parameters. Both files were merged and transformed to a shape file through ArcGIS, connecting the information from the key points with their position in the ventilation layout using the Universal Transverse Mercator projection (UTM) as a reference system. The merger process requires a standardised format for the database, otherwise problems can arise in the pre-processing stage.

\subsection{Pre-processing}

For the construction of the GIS file, these maps and ventilation data have been divided in different layers regarding two conditions: principal and auxiliary circuit with regard to every ventilation layout. This division makes the database management easier since they have different features and therefore separate analyses are required. Next step was to adequate the database storage from 
each point, taking into account the division previously described and the calculation of parameters such as airflow or effective temperature by means of the ArcGIS tools, which allow to introduce simple formulas. These equations are indicated in the following Section 3.3.1.

\subsubsection{Ventilation parameters description}

The parameters described below are either measured in situ or calculated using the initial data. 18 parameters concerning the principal ventilation system and 22 in the auxiliary have been chosen to stand for the ventilation conditions. Each parameter is a column in database.

\subsubsection{Principal ventilation.}

- Point: Identification number.

- Coordinates (UTM): Position of the point.

- Date of the measure: Hour, day, month and year.

- Air velocity $(\mathrm{m} / \mathrm{s})$ : Measured with a rotating vane anemometer.

- Dry and wet temperature $\left({ }^{\circ} \mathrm{C}\right)$ : Using a sling psychrometer.

- Carbon monoxide, $\mathrm{CO}$ (ppm), carbon dioxide, $\mathrm{CO}_{2}$ (ppm), nitric oxide, $\mathrm{NO}(\mathrm{ppm})$, nitrogen dioxide $\mathrm{NO}_{2}(\mathrm{ppm})$ and oxygen, $\mathrm{O}_{2}$ (\%). Determined by a gas detector.

- Section $\left(\mathrm{m}^{2}\right)$ : Calculated with a laser distance measurer.

- Airflow $\left(\mathrm{m}^{3} / \mathrm{s}\right)$ : Using the next expression. Airflow = Air velocity $\times$ Section.

- Effective temperature $\left({ }^{\circ} \mathrm{C}\right)$ : Through the equation stated by the Spanish law (RGNBSM, itc 04.7.02), te $=0.9 \cdot \mathrm{tw}+0.1 \cdot \mathrm{td}$. Where te is effective temperature, tw wet temperature and td dry temperature.

- $\mathrm{NO}+\mathrm{NO}_{2}$ (ppm): $\mathrm{NO}$ and $\mathrm{NO}_{2}$ have to be summarised as the Spanish law requires (RGNBSM, itc 04.7.02) to know if it is below the threshold limit value (TLV-TWA), which is the maximum level that a worker can be exposed day after day without adverse health effects.

\subsubsection{Auxiliary ventilation.}

- Continuous miner: Identification number.

- Miner state: Working or in standby during the measures.

- Coordinates (UTM): Position of the miner.

- Date of the measure: Hour, day, month and year.

- Air velocity $(\mathrm{m} / \mathrm{s})$ : Measured in front of the entry and exit of the pipeline.

- Pipe section $\left(\mathrm{m}^{2}\right)$ : Provided by the supplier.

- Airflow pipeline entry and exit $\left(\mathrm{m}^{3} / \mathrm{s}\right)$.

- Distance between working face and pipeline entry ( $\mathrm{m}$ ): Using a laser distance measurer.

- Type of fan: Exhausting, forcing or both.

- Other information: Any incident or remarkable situation.

- Dry, wet and effective temperature $\left({ }^{\circ} \mathrm{C}\right)$.

- $\mathrm{CO}$ (ppm), $\mathrm{CO}_{2}$ (ppm), $\mathrm{NO}$ (ppm), $\mathrm{NO}_{2}$ (ppm), $\mathrm{NO}+\mathrm{NO}_{2}$ (ppm) and $\mathrm{O}_{2}(\%)$.

\subsection{Database design and management}

Fig. 2 shows the structure of the GIS once the data has been properly introduced, organised and calculations are done. Each configuration is a different ventilation layout with the principal and the auxiliary circuits. The principal includes the intake, return, leakages and the points where measures are taken. Meanwhile, the auxiliary contains the continuous miner positions and ventilation ducts. In addition, the mine workings layer stand for all the tunnels exploited along the time.

On the other hand, Fig. 3 illustrates the steps followed to create the structure described above. Stages 1, 2 and 3 would be the same in the case of another sort of underground space, varying only the last two stages, 4 and 5 , in accordance with its specific characteristics.

The process explained is captured in Fig. 4, which is one of the configurations with the airflows painted as in Fig. 1. In addition,

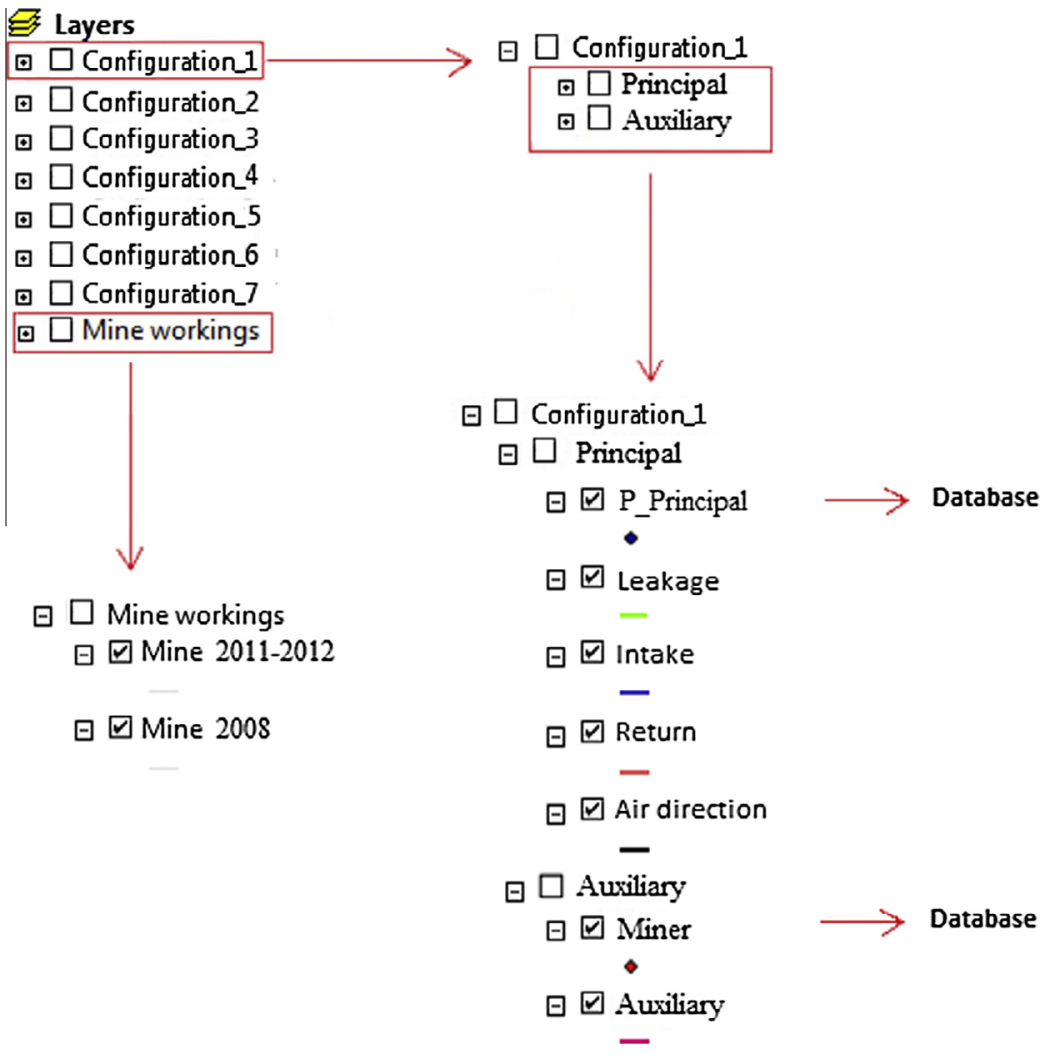

Fig. 2. Internal structure of the geographic information system. 


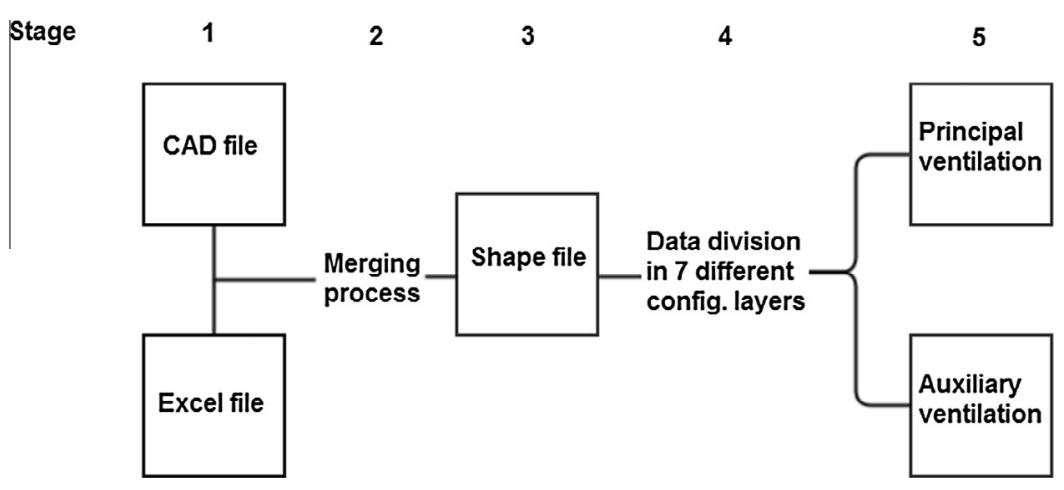

Fig. 3. Scheme of the process followed to create the GIS file.

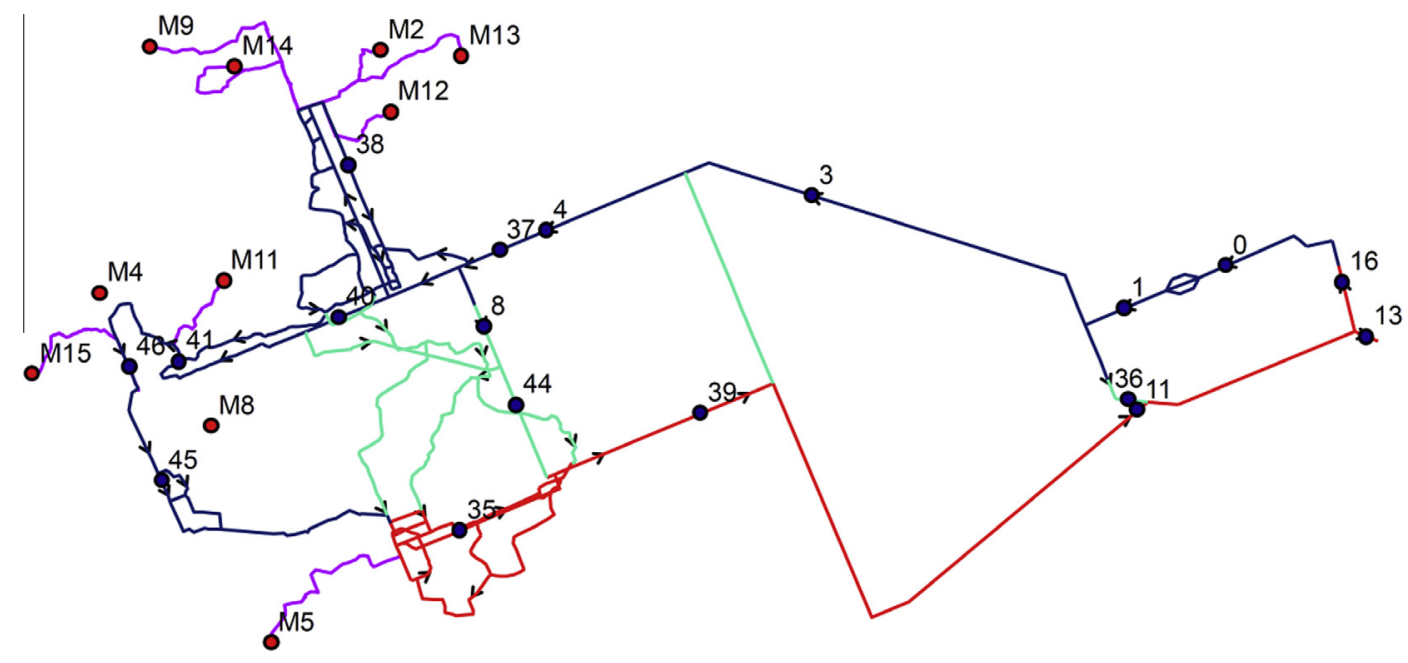

Fig. 4. Ventilation circuit in configuration 7.

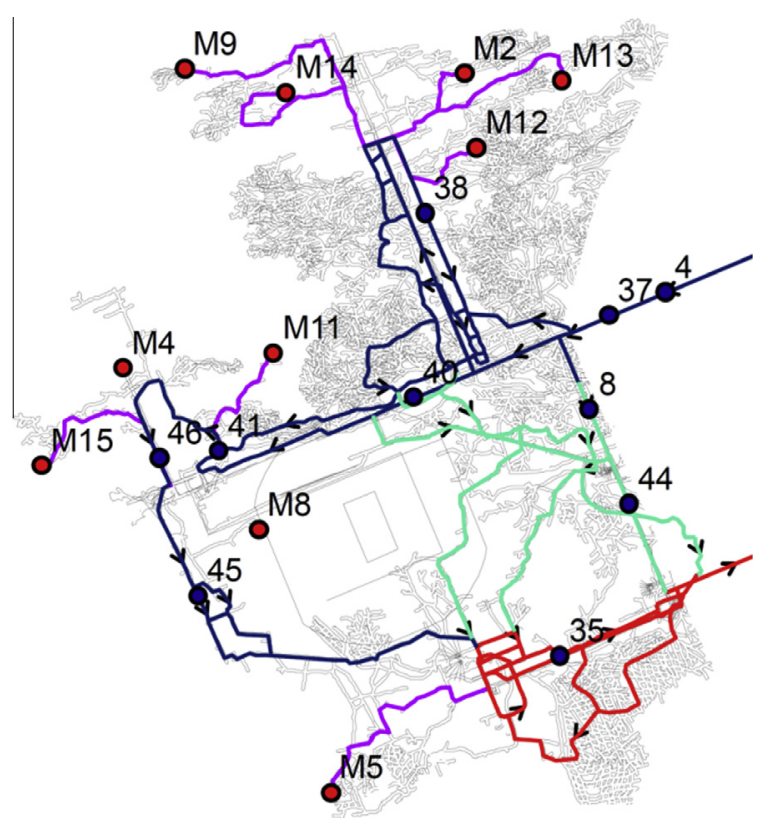

Fig. 5. Part of a ventilation circuit in detail with the mine workings layer activated.

there are some points that represent the places where measures are taken. The dots called "Mxx" are continuous miners, while the numbers " $x x$ " are control points from the principal circuit.
Furthermore, Fig. 5 is an image of part of the ventilation circuit and mine workings. Both layers - displayed at the same time - are useful to understand the airflow route and relate the ventilation system with the mine planning.

Table 1 shows part of the data stored and how is organised inside the GIS. Once the database is linked to the graphical information, the system can be inquired depending on the necessities of the space and extract results using the GIS tools. The initial excel file can also be linked to the software and update automatically the system with new data introduced, as well as carry out the calculations stated in Section 3.3.1.

Overall, the GIS gives an important connection among visual information, ventilation parameters and evolution of the mine along the time. The fact that all the data is connected and georeferenced in a database provides a very useful tool to control and analyse the reality of an underground environment in a long term and make future research in the field.

\section{Further improvements and applications}

The system could be automatised instead of taking in situ measures and provide real time operating data, which would help to improve safety aspects and the efficiency of the whole mine (Mitchell et al., 1986). Currently, there are several software that are able to simulate the environmental conditions of a mine, but the feedback between the simulation and the real situation is quite new. Although some underground facilities start using the software simulator, monitoring the conditions and using the collected 
Table 1

Data from the principal ventilation system in configuration 4 .

\begin{tabular}{|c|c|c|c|c|c|c|c|}
\hline Point & $X$ & $Y$ & Velocity $(\mathrm{m} / \mathrm{s})$ & Section $\left(\mathrm{m}^{2}\right)$ & Airflow $\left(\mathrm{m}^{3} / \mathrm{s}\right)$ & $\operatorname{Td}\left({ }^{\circ} \mathrm{C}\right)$ & $\operatorname{Tw}\left({ }^{\circ} \mathrm{C}\right)$ \\
\hline 0 & 406,644 & $4,632,795$ & 4.52 & 40.00 & 180.80 & 16 & 13 \\
\hline 1 & 406,299 & $4,632,649$ & 5.30 & 34.54 & 183.06 & 22 & 17 \\
\hline 36 & 406,312 & $4,632,339$ & 1.20 & 31.84 & 38.21 & 24 & 17 \\
\hline 3 & 405,239 & $4,633,032$ & 4.30 & 34.04 & 146.37 & 22 & 17 \\
\hline 4 & 404,338 & $4,632,913$ & 4.25 & 27.86 & 118.41 & 27 & 18 \\
\hline 37 & 404,179 & $4,632,847$ & 0.40 & 34.80 & 13.92 & 28 & 23 \\
\hline 34 & 404,875 & $4,632,946$ & 0.60 & 28.37 & 17.02 & 27 & 21 \\
\hline 7 & 405,059 & $4,632,507$ & 0.41 & 23.86 & 9.78 & 31 & 23 \\
\hline 8 & 404,125 & $4,632,587$ & 0.41 & 31.54 & 12.93 & 35 & 22 \\
\hline 38 & 403,666 & $4,633,134$ & 1.37 & 32.29 & 44.24 & 31 & 20 \\
\hline 35 & 404,044 & $4,631,896$ & 3.96 & 27.83 & 110.21 & 38 & 28 \\
\hline 39 & 404,861 & $4,632,294$ & 5.08 & 26.89 & 136.60 & 37 & 25 \\
\hline 11 & 406,344 & $4,632,305$ & 6.18 & 24.36 & 150.54 & 32 & 25 \\
\hline 13 & 407,122 & $4,632,553$ & 4.90 & 35.96 & 176.20 & 33 & 24 \\
\hline 16 & 407,039 & $4,632,738$ & 0.45 & 21.61 & 9.72 & 34 & 24 \\
\hline 40 & 403,634 & $4,632,619$ & 1.52 & 31.33 & 47.62 & 32 & 21 \\
\hline
\end{tabular}

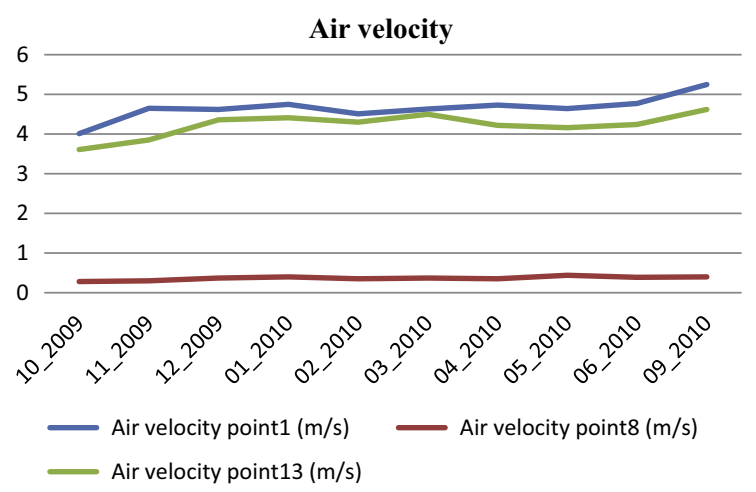

Fig. 6. Air velocity of the points 1,8 , and 13 from configuration 2 .

Table 2

Gases concentration comparison between points 1 and 13 .

\begin{tabular}{lrrlllr}
\hline Month & Year & Day & $\mathrm{NO}(\mathrm{ppm})$ & $\mathrm{NO}_{2}(\mathrm{ppm})$ & $\mathrm{CO}(\mathrm{ppm})$ & $\mathrm{CO}_{2}(\mathrm{ppm})$ \\
\hline Point 1 & & & & & & \\
October & 2009 & 23 & 0.00 & 0.00 & 0.00 & 0.00 \\
November & 2009 & 26 & 0.00 & 0.00 & 0.00 & 0.00 \\
December & 2009 & 1 & 0.00 & 0.00 & 0.00 & 0.00 \\
January & 2010 & 11 & 0.00 & 0.00 & 0.00 & 0.00 \\
February & 2010 & 25 & 0.00 & 0.00 & 0.00 & 0.00 \\
March & 2010 & 24 & 0.00 & 0.00 & 0.00 & 0.00 \\
April & 2010 & 4 & 0.00 & 0.00 & 0.00 & 0.00 \\
May & 2010 & 17 & 0.00 & 0.00 & 0.00 & 0.00 \\
June & 2010 & 18 & 0.00 & 0.00 & 0.00 & 0.00 \\
September & 2010 & 20 & 0.00 & 0.00 & 0.00 & 0.00 \\
Point 13 & & & & & & \\
October & 2009 & 23 & 5.00 & 0.20 & 8.00 & 2500.00 \\
November & 2009 & 26 & 5.00 & 0.20 & 8.00 & 2800.00 \\
December & 2009 & 1 & 5.00 & 0.20 & 9.00 & 3000.00 \\
January & 2010 & 11 & 1.00 & 0.00 & 0.00 & 500.00 \\
February & 2010 & 25 & 2.00 & 0.00 & 4.00 & 1900.00 \\
March & 2010 & 24 & 0.00 & 0.00 & 1.00 & 1500.00 \\
April & 2010 & 4 & 0.00 & 0.20 & 0.00 & 800.00 \\
May & 2010 & 17 & 6.00 & 0.10 & 4.00 & 2100.00 \\
June & 2010 & 18 & 0.00 & 0.10 & 7.00 & 400.00 \\
September & 2010 & 20 & 4.00 & 0.00 & 0.00 & 100.00 \\
\hline
\end{tabular}

data to give feedback between the simulation and the real situation (Ruckman and Prosser, 2010), the GIS could be an intermediate step between the data gathered and the simulation because it is more efficient discriminating the information by means of knowledge and necessities of the technicians.

Moreover, the system proposed can be extrapolated to other spaces instead of a mine, such as tourist caves, confined spaces or any underground infrastructure where environmental conditions have to be controlled.

\section{Results and discussion}

The following results are obtained from the analysis of the data collected in situ and processed by the GIS, either the principal or the auxiliary ventilation system, giving some approaches of the possible assessments that can be achieved. The most sensitive characteristics of the ventilation system are set out below.

\subsection{Principal ventilation system}

\subsubsection{Air velocity}

It is a key parameter for health and safety, operation costs and modelling the airflow necessities of the principal and auxiliary circuit considering the number of workers, gases produced by diesel engines, necessity to remove excessive temperature and maximum air velocity permitted by law. Gas concentrations and temperature increase rapidly without an adequate air supply, worsening the workplace conditions and efficiency rate of the employees. Fig. 6 displays an air velocity evaluation, from data collected in situ, in three different chosen points from the principal circuit.

Point 1 is at the beginning of the ventilation circuit after the main fan, while 13 is the last one before the airflow, in the return, flows to the surface. On the other hand, point 8 is in an intermediate position. The system created can assess the air velocity taking into account the different ventilation layouts.

\subsubsection{Gases}

Points 1 and 13 have been used once more to compare the quantity of gases. Table 2 shows that the first one does not have any concentration of gases, while it is significantly higher in the return. Despite that, values always remain under the TLV specified by the Spanish law, ITC 04.7.02.

Additionally, Fig. 7 illustrates the location of the measures taken and used in Table 2. It clarifies the airflow route and gives some clues about where the main sources of gases could be. Therefore, efforts can be focused on the most adverse zones and subsequently control the effectiveness of any remedial action.

\subsection{Auxiliary ventilation system}

\subsubsection{Effective temperature}

When temperature is kept below a certain value, the efficiency of the mine increases, because the workforce is able to stay more time in the working faces, according to the law, with a higher 


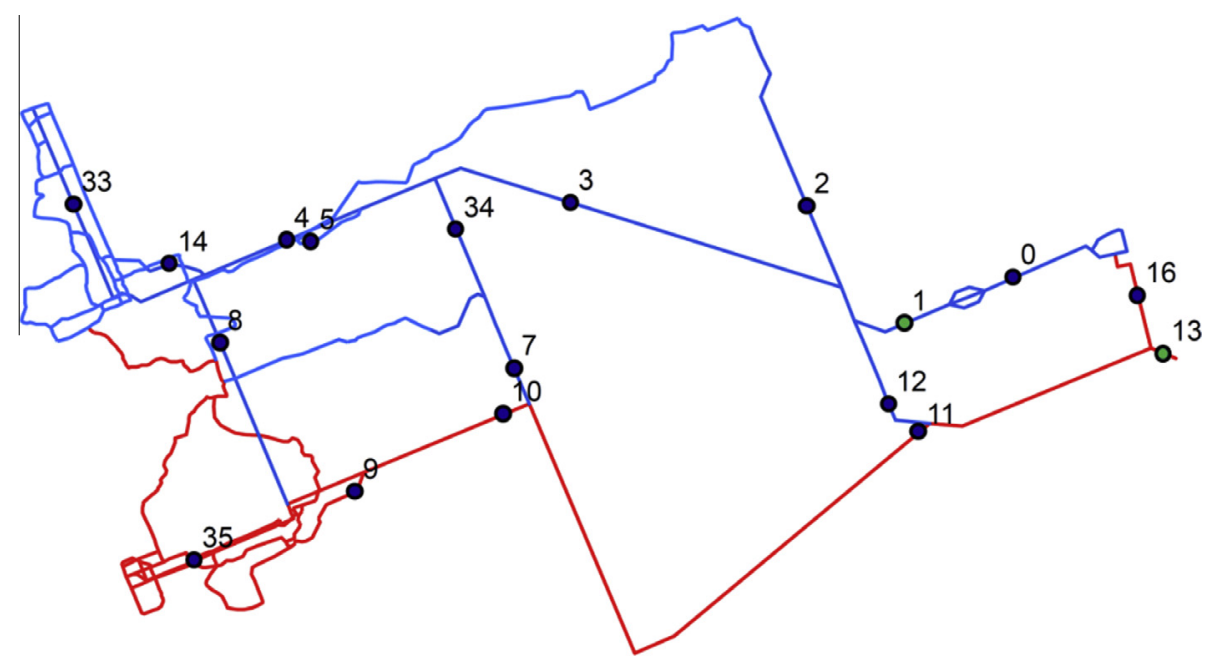

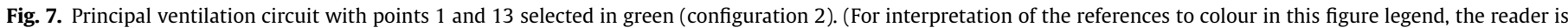
referred to the web version of this article.)

Table 3

Selection of the measures over $30{ }^{\circ} \mathrm{C}$ during 2012 .

\begin{tabular}{llllll}
\hline Miner & $X$ & $Y$ & Month & Day & Te $\left({ }^{\circ} \mathrm{C}\right)$ \\
\hline M5 & 403,584 & $4,631,491$ & February & 21 & 34.40 \\
M5 & 403,501 & $4,631,512$ & April & 21 & 32.10 \\
M11 & 403,192 & $4,632,604$ & April & 21 & 31.00 \\
M15 & 402,635 & $4,632,536$ & April & 21 & 30.20 \\
M7 & 403,423 & $4,631,908$ & May & 23 & 30.00 \\
M11 & 403,198 & $4,632,596$ & May & 23 & 31.00 \\
M14 & 403,016 & $4,633,352$ & October & 19 & 30.80 \\
M2 & 404,010 & $4,633,606$ & October & 19 & 32.00 \\
M12 & 403,802 & $4,633,316$ & October & 19 & 32.50 \\
M6 & 404,061 & $4,631,677$ & October & 19 & 31.80 \\
M5 & 403,500 & $4,631,509$ & October & 19 & 33.80 \\
M7 & 403,521 & $4,631,717$ & October & 19 & 30.00 \\
M5 & 403,403 & $4,631,515$ & November & 22 & 30.00 \\
M11 & 403,243 & $4,632,742$ & November & 22 & 31.10 \\
\hline
\end{tabular}

mental concentration (Garcia-Herrero et al., 2012). Table 3 comprises a selection, using the GIS tools, of the miners that have been over $30^{\circ} \mathrm{C}$ during 2012 , while Fig. 8 displays the location of these miners.
As it can be seen, only 14 in 156 measures from 2012 have exceeded the conditions imposed. Using the GIS, it is possible to detect adverse conditions more easily and quickly. Knowing when it has happened, how many times and which parts are the most negative with regard to health and safety.

\subsubsection{Relationship temperature-gases-airflow}

Several features can also be studied together. Fig. 9 relates all the data collected concerning temperature, gases and airflow from the auxiliary circuit (159 measures in total). Unfortunately, there is a short period without $\mathrm{CO}$ and airflow measures. The concentration of the $\mathrm{CO}_{2}$ (in ppm) has been divided per 100 to get a more visual chart.

As it can be seen, there is a correlation between temperature, gases and airflow. The larger the airflow is, the higher the temperature and the gases concentration are. The air, supposedly clean, flows from a working face to another, carrying part of the gases from the previous miner and so on. This approach can be useful to assess any change in the auxiliary system and to find unwanted local airflow recirculation.

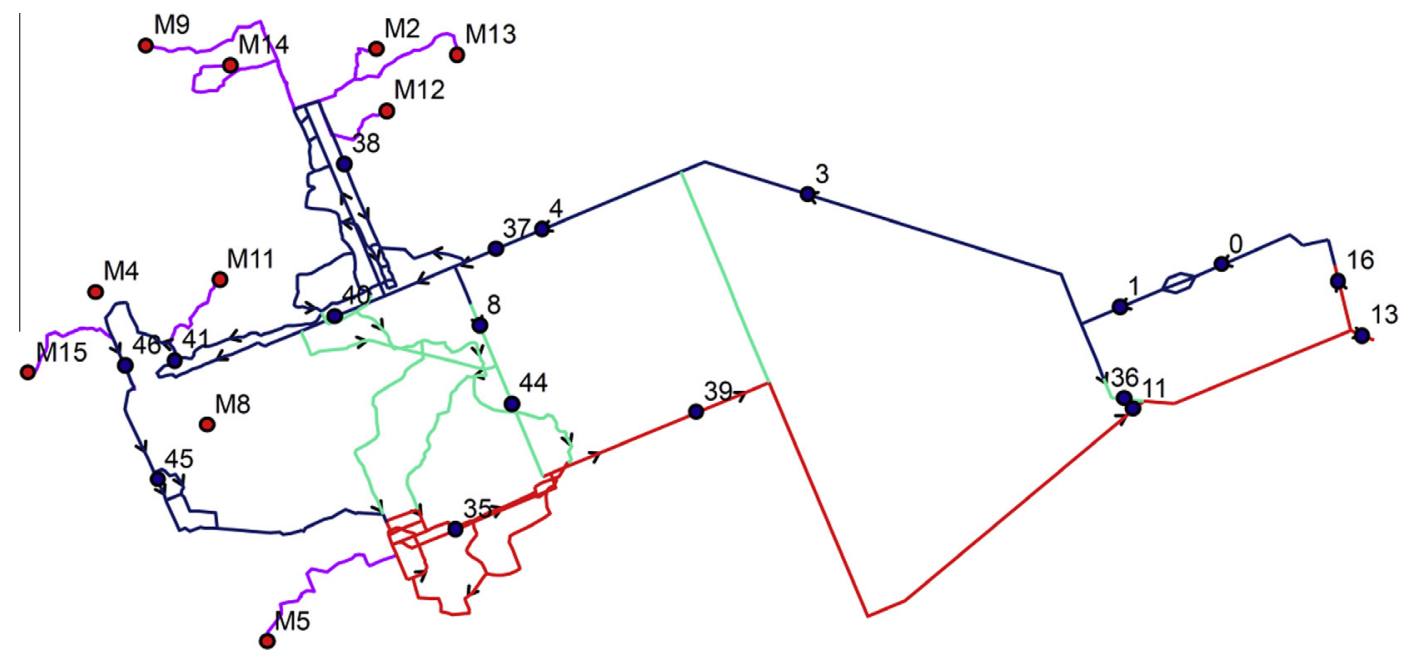

Fig. 8. Principal and auxiliary ventilation system with the control points and miners position (configuration 7). 
Relationship temperature-gases-airflow

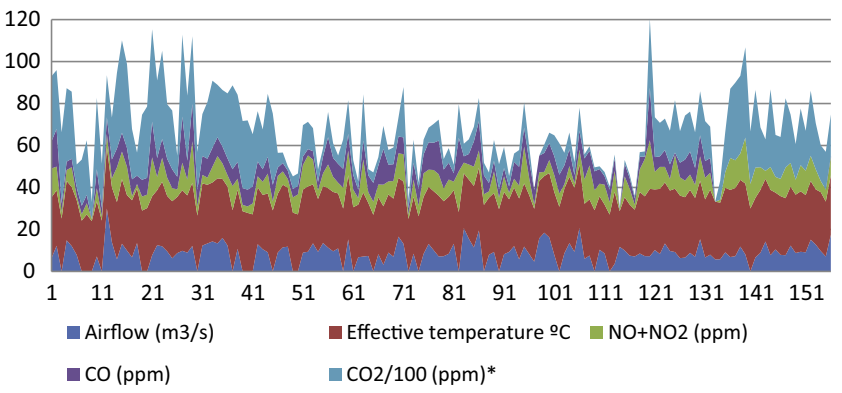

Fig. 9. Values of temperature, gases and airflow from the auxiliary ventilation system.

\subsection{Other possible outcomes}

Although the core issues of the case study have already been treated, the capabilities of the GIS could be focused on other aspects depending on the underground space and its specific necessities.

\section{Conclusions}

The GIS created has been confirmed as a powerful tool to provide a safer and healthier work environment and improve the efficiency of the ventilation system. The connection of both concepts is crucial to make any decision that concerns applying changes to the ventilation system and the use of the geographic information system can be helpful for such purpose. In addition, the possibility to complement the GIS with other software and include other factors when it is necessary gives an enormous flexibility to control an underground environment.

In this case, the system has given insight of the most sensitive parts concerning gases, temperature, air velocity and airflow in the principal and auxiliary ventilation circuits. The factors have been assessed individual and collectively. Specifically, the variations of velocity and gases concentration along the principal circuit have been obtained using all the historical data. Meanwhile, the most adverse working faces in terms of effective temperatures and gases concentration have also been studied. In the auxiliary system, a pattern among airflow, gases concentration and effective temperature has also been found.

\section{Acknowledgements}

This research has been carried out by the Iberpotash Chair in mining sustainability in collaboration with ICL-Iberia. The authors would like to thank the staff of the mine for their willingness as well as the postgraduate students A. Galera and D. Flores for important contributions to create the database.

\section{References}

Akcil, A., 2006. Managing cyanide: health, safety and risk management practices at Turkey's Ovacik gold-silver mine. J. Clean. Prod. 14 (8), 727-735.

Alfonso Abella, M.P., Sanmiquel Pera, L.L., Vintro Sanchez, C., Parcerisa Duocastella, D., Oliva Moncunill, J., Freijo Alvarez, M., Mata Perelló, J.M., 2013. Development of an integrated monitoring system for touristic mines and caves. In: International Conference on Sustainable Tourism and Cultural Heritage, pp. 303-307.

Allen, C., Inco, V., Keen, B., 2008. Ventilation on demand (VOD) project - Vale Inco Ltd., Coleman Mine. In: 12th North American Mine Ventilation Symposium 2008, pp. $45-50$.

Cheng, J., Yang, S., 2012. Data mining applications in evaluating mine ventilation system. Saf. Sci. 50 (4), 918-922.

Düzgün, Ş., Künzer, C., Özgen Karacan, C., 2011. Applications of remote sensing and GIS for monitoring of coal fires, mine subsidence, environmental impacts of coal-mine closure and reclamation. Int. J. Coal Geol. 86 (1), 1-2.

Garcia-Herrero, S., Mariscal, M.A., García-Rodríguez, J., Ritzel, D.O., 2012. Working conditions psychological physical symptoms and occupational accidents. Bayesian network models. Saf. Sci. 50, 1760-1774.

Gibert, K., Sànchez-Marrè, M., Rodríguez-Roda, I., 2006. GESCONDA: an intelligent data analysis system for knowledge discovery and management in environmental databases. Environ. Model. Softw. 21 (1), 115-120.

Hargreaves, D.M., Lowndes, I.S., 2007. The computational modelling of the ventilation flows within a rapid development drivage. Tunn. Undergr. Space Technol. 22, 150-160.

Kim, K.-D., Lee, S., Oh, H.-J., Choi, J.-K., Won, J.-S., 2006. Assessment of ground subsidence hazard near an abandoned underground coal mine using GIS. Environ. Geol. 50 (8), 1183-1191.

Kurnia, J.C., Sasmito, A.P., Mujumdar, A.S., 2014. Simulation of a novel intermittent ventilation system for underground mines. Tunn. Undergr. Space Technol. 42, 206-215.

Likar, J., Čadež, J., 2000. Ventilation design of enclosed underground structures. Tunn. Undergr. Space Technol. 15 (4), 477-480.

Lipsey, M.W., 1990. Design Sensitivity. Sage Publications, Newbury Park, California.

Liu, H., Yang, D., City, H., 2004. GIS-based mine ventilation network and safety analysis. In: IEEE International Geoscience and Remote Sensing Symposium Proceedings, vol. 5, pp. 2945-2948.

McPherson, M.J., 2009. Subsurface Ventilation and Environmental Engineering. California, USA, ISBN: 978-0-692.00024-3.

Mitchell, J., Eros, L., King, R., 1986. Deserado mine computer monitoring and control system. In: Proceedings of the Eighth WVU Mining Electro Technology Conference.

Puliafito, E., Guevara, M., Puliafito, C., 2002. Characterization of urban air quality using GIS as a management system. Environ. Pollut.

Reddy, A.C., 2009. Development of a Coal Reserve GIS Model and Estimation of the Recoverability and Extraction Costs. Master of Science Thesis. Department of Mining Engineering, West Virginia University.

Ruckman, R., Prosser, B., 2010. Integrating ventilation monitoring sensor data with ventilation computer simulation software at the Waste Isolation Pilot Plant facility. In: 13th United States/North American Mine Ventilation Symposium, vol. 96, pp. 237-242.

Şalap, S., Karslığlu, M.O., Demirel, N., 2009. Development of a GIS-based monitoring and management system for underground coal mining safety. Int. J. Coal Geol. 80 (2), 105-112.

Saleh, J.H., Cummings, A.M., 2011. Safety in the mining industry and the unfinished legacy of mining accidents: safety levers and defense-in-depth for addressing mining hazards. Saf. Sci. 49 (6), 764-777.

Shannon, H.S., Robson, L.S., Guastello, S.J., 1999. Methodological criteria for evaluating occupational safety intervention research. Saf. Sci. 31, 161-179.

Toraño, J., Torno, S., Menéndez, M., Gent, M., 2011. Auxiliary ventilation in mining roadways driven with roadheaders: validated CFD modelling of dust behaviour. Tunn. Undergr. Space Technol. 26, 201-210. 